San Jose State University

SJSU ScholarWorks

Master's Theses

Master's Theses and Graduate Research

Spring 2010

\title{
Predicting Work and Organizational Engagement with Work and Personal Factors
}

Andrea Kittredge

San Jose State University

Follow this and additional works at: https://scholarworks.sjsu.edu/etd_theses

\section{Recommended Citation}

Kittredge, Andrea, "Predicting Work and Organizational Engagement with Work and Personal Factors" (2010). Master's Theses. 3771.

DOI: https://doi.org/10.31979/etd.zx9f-e3wx

https://scholarworks.sjsu.edu/etd_theses/3771

This Thesis is brought to you for free and open access by the Master's Theses and Graduate Research at SJSU ScholarWorks. It has been accepted for inclusion in Master's Theses by an authorized administrator of SJSU ScholarWorks. For more information, please contact scholarworks@sjsu.edu. 


\title{
PREDICTING WORK AND ORGANIZATIONAL ENGAGEMENT WITH WORK
} AND PERSONAL FACTORS

\author{
A Thesis \\ Presented to \\ The Faculty of the Department of Psychology \\ San José State University \\ In Partial Fulfillment \\ of the Requirements for the Degree \\ Master of Science
}

by

Andrea A. Kittredge

May 2010 
(C) 2010

Andrea A. Kittredge

ALL RIGHTS RESERVED 
The Designated Thesis Committee Approves the Thesis Titled

\title{
PREDICTING WORK AND ORGANIZATIONAL ENGAGEMENT WITH WORK AND PERSONAL FACTORS
}

\author{
by
}

Andrea A. Kittredge

APPROVED FOR THE DEPARTMENT OF PSYCHOLOGY

SAN JOSÉ STATE UNIVERSITY

May 2010

Dr. Howard Tokunaga Department of Psychology

Dr. Megumi Hosoda Department of Psychology

Ms. Laura Gottlieb Stanford Hospital \& Clinics 


\section{ABSTRACT \\ PREDICTING WORK AND ORGANIZATIONAL ENGAGEMENT WITH WORK AND PERSONAL FACTORS \\ by Andrea A. Kittredge}

The current study examined how psychological hardiness and self efficacy would be related to both work engagement and organizational engagement after controlling for job characteristics, perceived organizational support, and procedural justice as work characteristics. Findings showed that psychological hardiness, specifically commitment, added significant predictive value to both work and organizational engagement after controlling for the work characteristics. However, commitment accounted for more variance in work engagement than variance in organizational engagement. Although it was correlated with overall hardiness, self efficacy was not found to be directly related to either engagement variable, nor did it add predictive value to either of the forms of engagement. Implications of the study are discussed. 


\section{ACKNOWLEDGEMENTS}

To my chair, Dr. Howard Tokunaga, to whom I owe a debt of gratitude. Over the course of five years I brought him two other unsuccessful proposals and each time he agreed to work with me until I finally got it right. I could never have finished without his infinite patience and unwavering support.

To Dr. Megumi Hosoda, to whom I also owe my eternal gratitude. Dr. Hosoda was not just my reader she was my advocate. When I had a question about a form or a process she was there for me and when I was putting my committee together she agreed to be my reader and contributed to my success.

To Laura Gottlieb, M.Ed., my colleague and committee member. By her example, Laura has shown me how to be a good coach to the management and employee population we serve together. Also, she has been my peer reviewer when dealing with a difficult professional issue and has been one of my "best friends" at work.

To my friends and colleagues who encouraged me over my seven year journey towards my M.S. Thank you to those who nagged me and would not give up on me until I finally went back and finished the job, especially Mildred DeLeon, Pooja Chakravarti, Edward Whitmore, Priya Margam, and Doug Van Kirk. Also, thank you to my managers, Deb and Ekta, for giving me the occasional half day off to come to the SJSU campus and keep my appointments while I collected data and had my many meetings with my chair and committee. 
To my family: My mother, Wendy, who listened to me when I whined about how it was "too hard." Also, to everybody else who would not listen to me whine because they knew I could do it: Alana, my sister; Michael, my dad; Cornelia, my grandmother; and my aunts and cousins. Thank you to my mother in law, Dr. Patricia Penn, for her gentle encouragement and to my husband Michael for reminding me of the importance of hard work and perseverance. 


\section{TABLE OF CONTENTS}

List of Tables......................................................................

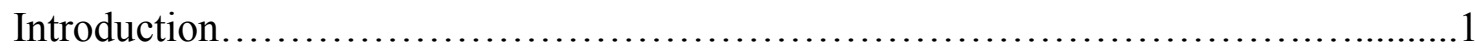

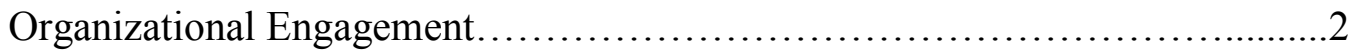

Burnout to Engagement: Measurement Issues....................................3

Perceived Organizational Support as an Antecedent of Engagement..............6

Antecedents of Work Engagement Versus Organizational

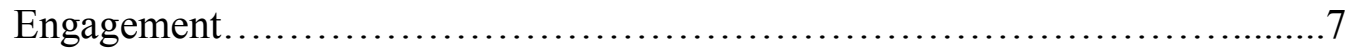

Personal Characteristics and Burnout...........................................10

The Goals of the Present Study................................................13

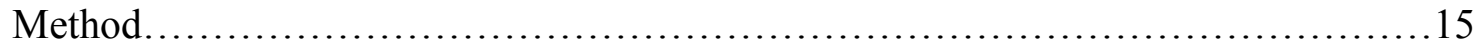

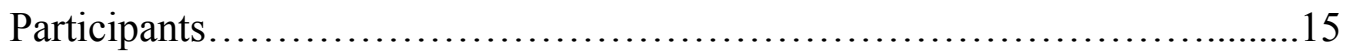

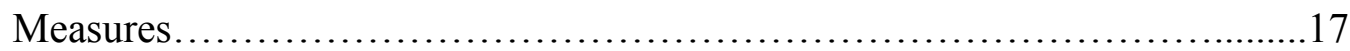

Perceived Organizational Support......................................17

Job Characteristics.................................................. 17

Procedural Justice.................................................... 17

Psychological Hardiness..............................................17

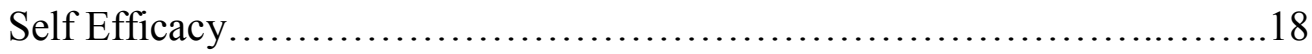

Work Engagement................................................. 18

Organizational Engagement............................................. 18

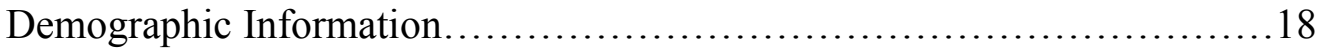

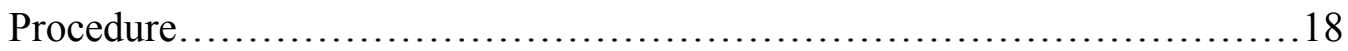

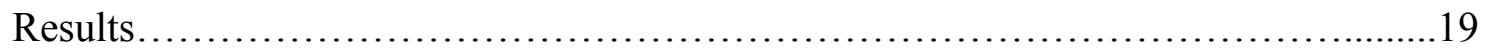

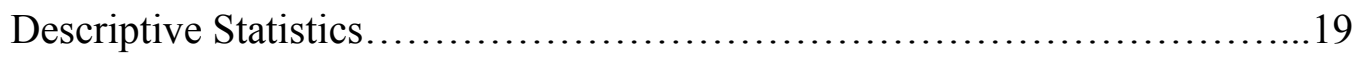




\section{TABLE OF CONTENTS}

(Continued)

Correlations Among the Measured

Variables...........................................................20

Tests of Hypotheses.................................................23

Exploratory Analyses..................................................... 30

Vigor....................................................................

Dedication.......................................................... 31

Absorption.............................................................. 32

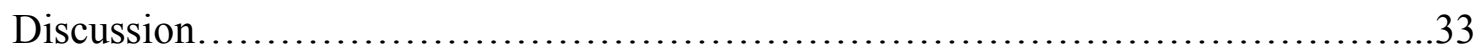

Study Implications..................................................... 37

Study Evaluation and Directions for Future Research.....................41

References.................................................................. 44

Appendix A: Survey Items..............................................52

Appendix B: IRB Approval to Conduct Research................................56 


\section{LIST OF TABLES}

Table 1. Highest Educational Level Reported by Participants ..............................16

Table 2. Descriptive Statistics for Work and Organizational Engagement ............21

Table 3. Correlations Among the Measured Variables........................................22

Table 4. Prediction of Overall Work Engagement by Work and Personal

Characteristics .........................................................................25

Table 5. Prediction of Organizational Engagement by Work and Personal

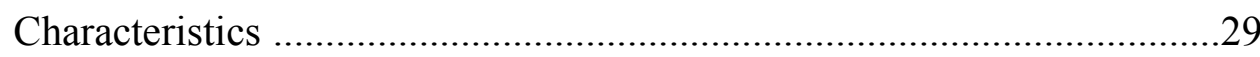

Table 6. Beta Weights for Work Engagement Overall and for Each

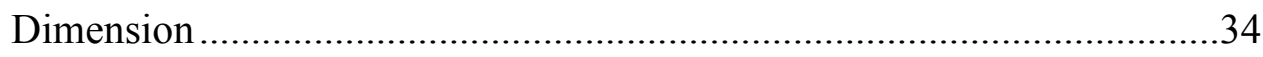


Introduction

Traditionally, organizations have invested into the study of employee job satisfaction to predict organizational outcomes such as role performance. However, a new line of research originating in the consulting industry (the Gallup Organization) now suggests that a new predictor, employee engagement, is key to organizational commitment and job performance (Freeney \& Tiernan, 2006). Engagement is also found to positively associate with psychosomatic health, motivation, and positive workplace attitudes (Schaufeli \& Salanova, 2007).

These emerging findings suggest that building an environment that fosters engagement might help overcome problems associated with workplace stress and dissatisfaction. As noted by Freeney and Tiernan (2006), engagement "has become the new human resources buzzword" (p. 130) and many organizations are replacing job satisfaction surveys with engagement questionnaires such as the Gallup Q12. As engagement builds popularity in the consulting industry, it is also building an interest onamg academics (e.g., Saks, 2006).

Kahn (1990) introduced the scholarly definition of engagement, arguing that engaged workers apply themselves to their work "physically, cognitively, and emotionally during role performance" (p. 692). In contrast, disengaged workers become withdrawn and defensive. Kahn also defined psychological conditions of engagement: meaningfulness, safety, and availability. Meaningfulness is the degree to which workers invest themselves into their role performances and experience a return on that investment, such as feeling valued by the employer. Safety implies that the employee feels 
comfortable to show the self without negatively impacting the self-image, status, or career. Availability is the worker's belief that he or she has the physical, emotional, and cognitive resources to engage the self in work.

\section{Organizational Engagement}

Previous research has focused primarily on employee's engagement in the work itself. However, Rothbard (2001) found that one's degree of engagement varies by the role in question. Drawing upon this premise, Saks (2006) considered the work role separate from the role as a member of the organization and conducted the first study to examine work engagement and organizational engagement independently. Saks defines organizational engagement as the sense of personal attachment to the company itself, independent of the individual's professional role within the organization.

Saks (2006) argues that organizational engagement is explained through Social Exchange Theory (SET). One of the basic principles of SET is that social relationships are built within the reciprocity rules of exchange. Accordingly, when workers receive socioemotional and economic resources from the employer entity, they feel obliged to give back, thus "repay" what they perceive that they owe to the organization.

Saks (2006) asserts that employees repay the organization with their level of engagement, dedicating their mental, physical, and emotional resources based on their assessment of what the employer has offered them. When workers perceive that the employer has not responded appropriately to their contributions, they will be more likely to become dejected and disengaged. However, for practical reasons, employees have a more difficult time lowering their actual job performance, as performance is concretely 
evaluated and used to make decisions about status and pay. Saks examined the relationship between work engagement and organizational engagement and found a significant, moderate correlation between the two $(r=.62)$. However, he noted that the means of the two variables were significantly different: Respondents reported higher work engagement when compared with organizational engagement.

Saks also found that work engagement and organizational engagement had different antecedents. These findings have practical significance for companies evaluating these constructs: Based on Saks's findings, employees who perceive high organizational support are more likely to experience greater levels of both work and organizational engagement. Employees who feel they have interesting and fulfilling work (i.e. roles encompassing autonomy, task identity, skill variety, task significance, and opportunities for performance feedback) are more likely to perceive higher work engagement but not necessarily higher organizational engagement. Finally, employees who have high perceptions of procedural justice are more likely to experience organizational engagement but not necessarily work engagement. By providing evidence that the means between work engagement and organizational engagement can differ significantly, Saks (2006) also provided empirical support that there is value in evaluating the two forms of engagement separately.

Burnout to Engagement: Measurement Issues

Much of the engagement model draws from the burnout literature (Bakker, Schaufeli, Leiter, \& Taris, 2008). Burnout was originally conceptualized as encompassing the dimensions of emotional exhaustion (the feeling of being drained by 
demanding interpersonal workplace interactions), depersonalization (negative, cynical attitudes towards the recipients of one's services), and lack of personal accomplishment (the negative assessment of one's work with recipients of services) (Maslach \& Jackson, 1986). Originally, burnout was only thought to occur among those who do "people work"- health care, social services, education, and other service oriented professions. All three dimensions of the original instrument, the MBI (Maslach Burnout Inventory, Maslach \& Jackson, 1981), refer to contact with other people as part of the job. Subsequent research across a broader base of occupations led to the development of the MBI General Survey (MBI-GS), and later to an expanded concept of its proposed opposite: employee engagement.

Maslach and Leiter (1997) propose that engagement is evidenced by energy, involvement, and professional efficacy -- the direct opposites of the three burnout dimensions of the MBI-GS (adapted by Schaufeli, Leiter, Maslach, \& Jackson, 1996). Accordingly, low scores on exhaustion and cynicism (a more generic concept of depersonalization) and high scores on the efficacy dimension (similar to personal accomplishment, but not contingent on people interaction) would indicate engagement. However, Schaufeli, Salanova, Gonzalez-Roma, and Bakker (2002) challenged the validity of the opposites concept, arguing that using the MBI-GS to study both burnout and engagement has limited empirical use. They propose that while burnout and engagement are opposite constructs, they should be measured independently with different instruments because it is possible that not all of the burnout dimensions are on the same continuum as the opposing engagement dimensions. 
Schaufeli and Bakker (2001) (as cited in Schaufeli et al., 2002) identified two dimensions of work-related well being that have the opposing relationships with burnout and engagement: activation and identification. Activation ranges on a continuum from exhaustion to vigor and identification ranges from cynicism to dedication. Burnout is evidenced by low activation (exhaustion) and low identification (cynicism), and engagement is indicated by high activation (vigor) and high identification (dedication). However, Schaufeli et al. (2002) argue that absorption (the act of fully being engrossed in one's work) is the third dimension of the engagement model. On this dimension, burnout and engagement are not empirical opposites because low professional efficacy (negative evaluation of one's work) is not the reverse of high absorption.

Schaufeli et al. (2002) define work engagement as a fulfilling, work-related state of mind. They further argued that the persistent state of work engagement is not directed specifically at any work place object, event, individual, or behavior. They proposed that engagement consisted of the three factors: vigor, dedication, and absorption. They tested their three-factor engagement model using 314 university students and 619 workers from various disciplines at 12 private and public sector institutions in Spain. The researchers assessed the factorial structure of the MBI-GS and examined the empirical relationship between burnout and engagement. Confirmatory factor analyses in both samples confirmed the three factor burnout model (exhaustion, cynicism, and professional efficacy) and supported their hypothesized structure of engagement. The data they collected resulted in the development of the original 17-item Utrecht Work Engagement Scale (UWES). 
In a follow up study, Schaufeli, Bakker, and Salanova (2006) collected data from 10 countries to confirm the three factor structure of engagement as earlier proposed. The findings of the study confirmed the factor structure and led to the refinement of the instrument, resulting in the nine-item short version of the UWES. The factor structure of the nine item instrument was assessed with confirmatory factor analyses and the three factor scores showed good internal consistency and test-retest reliability. Further validation of the UWES (Seppala et al., 2009) supports the continued use of the nine item instrument. They find that the nine item instrument demonstrates good construct validity, and the factor structure remains relatively unchanged across samples and across time. Freeney and Tiernan (2006) have also commented on the merits of the UWES, noting that it is a suitable measure for academic study because it has been psychometrically evaluated. Gallup has not published details of the psychometric properties of the Q12 scale, and does not give permission for the scale to be used for academic purposes. Perceived Organizational Support as an Antecedent of Engagement

In addition to the factor structure of work engagement, its antecedents and consequences have also been examined. While Schaufeli et al. (2002) focused on refining the study of work engagement, Saks (2006) evaluated work and organizational engagement separately. He found that work engagement and organizational engagement share a common antecedent variable: perceived organizational support (POS). POS is the workers' general belief that the employer values their service and is concerned for their well being (Rhoades \& Eisenberger, 2002). May, Gilson, and Harter (2004) found that individuals who had a sense of supportive relationships with their coworkers and 
supervisors experienced a stronger sense of psychological safety, which Kahn (1990) identified as one of the psychological conditions of engagement. Safety implies that the employee feels comfortable to show the self without negatively impacting the self-image, status, or career (Kahn, 1990).

Because employees view their relationship with their first line supervisors as an indicator of the company's support, positive relationships with one's supervisor also promote safety perceptions and employee engagement (Deci \& Ryan, 1987). Supervisors can foster a supportive work environment by displaying concern for the needs and feelings of employees, providing them with feedback, encouraging them to voice workplace concerns, and facilitating new skill development and problem solving skills (Deci \& Ryan, 1987). Supportive actions by the supervisor enhance employee selfdetermination (Deci, Connell, \& Ryan, 1989). Employees who are self determined are more likely to experiment with novel ways to do the work and try to learn from their mistakes (Edmondson, 1996, 1999).

Antecedents of Work Engagement Versus Organizational Engagement

Saks (2006) argues that while work engagement and organizational engagement are related, they are distinct constructs influenced by different factors. He found that work engagement is driven by job characteristics, while organizational justice influences organizational engagement. The finding that job characteristics drive work engagement is consistent with Kahn's argument that meaningfulness (one of the psychological conditions of engagement he identified) is related to the work tasks themselves. Meaningfulness is the degree to which workers feel self-fulfillment in the performance of 
their job roles (Freeney \& Tiernan, 2006). Hackman and Oldham (1980) argue that jobs should be designed in a way that they provide skill variety, task identity, task significance, autonomy, and feedback on results. Meaningful work fosters personal growth and employee motivation (Spreitzer, Kizilios, \& Nason, 1997). When workers feel a sense of purpose in their roles, there is improvement in organizational performance (e.g., productivity) (Neck \& Milliman, 1994), retention of top talent, effective change management, greater commitment, and engagement (Holbeche \& Springett, 2004; Milliman, Czaplewski, \& Ferguson, 2003). Saks (2006) findings are also consistent with earlier work by May et al. (2004), who found that job enrichment and psychological meaningfulness were positively correlated. May et al. further observed that the relationship between job enrichment and engagement was mediated by psychological meaningfulness.

In contrast, Saks (2006) argued that organizational justice perceptions were important predictors of organizational engagement because when employees interpret organizational fairness as representative of its good will, they are more likely to reciprocate with actions of good will towards the employer. Fairness is judged by the consistency and predictability of the organizational decision-making process, as shown by its distribution of rewards and design of procedures to rule how rewards are allocated. Perceptions of distributive justice relate to the fairness of organizational decision making outcomes and procedural justice is determined by perceptions that the decision process is fair. (Colquitt, 2001; Rhoades, Eisenberger \& Armeli, 2001). Saks argued that perceptions of procedural and distributive justice would relate to both work and 
organizational engagement. He found evidence only to support that procedural justice was related to organizational engagement. He did not find evidence that distributive justice predicted organizational engagement.

The findings of the Saks (2006) study provide valuable insight into the differences between work and organizational engagement, establishing the empirical value of examining the two forms of engagement separately. First, he found different antecedents influence the two forms of engagement. Second, he found that his participants reported higher work engagement than organizational engagement, establishing that employees evaluate their engagement towards their work separately from their engagement towards their organization. Finally, he observed that when compared with work engagement, organizational engagement was a stronger predictor of the outcomes he measured: job satisfaction, organizational commitment, intention to quit, and organizational citizenship behavior.

While Saks (2006) established possible differences between work and organizational engagement, it is still unclear whether or not engagement is driven purely by situational factors or if it partly relates to personality traits inherent to the individuals. Saks, as well as earlier researchers (Freeney \& Tiernan, 2006), point out that the exploration of this question is important to furthering the understanding of what drives engagement. Therefore, the goal of the current study is to further the line of research and explore organizational factors along with an additional set of proposed antecedent variables -- personal characteristics. 
To extend the knowledgebase, Saks (2006) suggests incorporating specific personal characteristics that are the established predictors of burnout -- psychological hardiness and self efficacy. Psychological hardiness is the psychological tendency to derive a sense of purpose from stressful events (Kobasa, 1979; Kobasa, Maddi, \& Kahn, 1982). Self efficacy is the overall belief that one is capable of mastering tasks and coping well with adversity (Bandura, 1986; Schwartzer, 1992).

Maslach, Schaufeli, and Leiter (2001) report that individuals who score low on hardiness have higher burnout scores, particularly on the exhaustion dimension. Based on Schaufeli and Bakker's (2001) premise that exhaustion and vigor are the opposite of the same continuum (activation), it is reasonable to assume that if low hardiness yields exhaustion, then higher scores on hardiness should be indicative of engagement (vigor). Self efficacy is also thought to be related to engagement. According to Leiter and Maslach (1998), engagement leads to the energetic state of involvement with personally fulfilling activities, thus enhancing one's sense of professional efficacy. Self-efficacious individuals believe that they are capable of mastering tasks and coping well with adversity, they become involved with personally fulfilling activities, and consequently more likely to become engaged. It is proposed that hardiness and self efficacy should add predictive value to the study of engagement.

\section{Personal Characteristics and Burnout}

This section defines psychological hardiness and self efficacy as they relate to work and organizational engagement. Psychological hardiness - the tendency to derive meaning from stressful events_-is a collection of three qualities: commitment to life and 
work, feelings of control over life events and outcomes, and the belief that change in life is a positive challenge, versus a threat (Kobasa, 1979). Hardy people demonstrating commitment tend to feel a sense of purpose that drives them to find meaning and value in a situation, so they are more inclined to show involvement versus alienation when faced with stressful events (Kobasa, 1979). Those who exercise control believe that they have the power to influence the outcomes of events in their lives. They do not believe that they are helpless to face the inevitable. Finally, hardy people tend to see change as an opportunity for personal growth. Rather than trying to preserve the status quo, hardy individuals strive for new challenges (Kobasa, 1979; Maddi \& Kobasa, 1984).

Theoretically, hardiness moderates the relationship between stressful events and burnout (Turnipseed, 1999). High stress and low hardiness have been observed to predict burnout in athletic directors (Martin, Kelley, \& Eklund, 1999). Specifically, athletic directors who tend to find career issues stressful and scored low in hardiness experienced higher stress and burnout. Similarly, among music therapists, proactive coping in stressful situation and higher levels of cognitive hardiness were associated negatively with burnout (Fowler, 2006).

The relationship between burnout and hardiness has also been extensively observed in both the nursing and teaching professions. Extensive studies consistently found that the lack of hardiness predicts burnout among nurses (Boyle, Grap \& Younger, 1991; Keane, Ducette, \& Adler, 1985; McCranie, Lambert, \& Lambert, 1987; Rich \& Rich, 1987; Topf, 1989). Conversely, Constantini, Solano, DiNapoli, and Bosco (1997) found that hardy student nurses experienced less burnout a year later. Likewise, 
Duquette, Kerouac, Sandhu, Ducharme, and Saulnier (1995) found that the main predictors of burnout among nurses are work stressors, work support, coping strategies, and hardiness. They further observed that hardy nurses committed to their lives and work and showed feelings of control in a situation.

The commitment aspect of hardiness was also found to be an important predictor of teacher burnout. Studies of teacher burnout have also looked at the specific correlates of hardiness and burnout. Findings have shown that social support, optimism, and hardiness negatively associate with exhaustion and depersonalization (Lopez et al., 2008) and that hardiness positively correlates with personal accomplishment (Lopez et al., 2008; Chan, 2003). Given that the research has established that hardiness is negatively correlated with burnout, it is expected that hardiness would be positively associated with engagement.

Self efficacy is another important variable in the study of burnout. Self efficacy is the belief that one can perform both new and difficult tasks successfully, and also cope well with adversity (Bandura, 1986; Schwartzer, 1992). Koeske and Koeske (1989) also argue that self efficacy is a way of coping that moderates the effects of exhaustion on mental distancing. Hence, low levels of self efficacy are indicative of burnout.

Schaufeli and Salanova (2007) agree that low self efficacy is indicative of burnout, but they challenge the measurement method of the reverse scoring of the MBI efficacy scale. Instead, they proposed that a new scale with negatively worded items would better measure inefficacy. They further argued that the positively worded items that measure efficacy would be associated with engagement. 
Basing their theory on the premise that efficacy and inefficacy are strong negative correlates, but not true empirical opposites (just as Schaufeli et al. (2002) argued that burnout and engagement are inversely related but not polar opposites), they developed a negatively worded scale to assess the relationship between inefficacy and burnout. They tested the instrument using two samples of university students (one Dutch sample and one Spanish) and two samples of Spanish workers from varying occupations. Using structural equation modeling to examine the fit of the data, they drew the following conclusions: inefficacy beliefs relate more strongly to the two burnout dimensions (exhaustion and cynicism) when compared with efficacy beliefs and a three factor burnout model replacing efficacy with inefficacy is a better fit for the data. Finally, the model with inefficacy loading on burnout and efficacy loading on engagement fits their data. Schaufeli, Bakker, and Salanova (2006) also observed that professional efficacy loads on engagement when they tested the factor structure of the UWES.

The goal of the Schaufeli and Salanova (2007) study was to assess the inefficacyburnout relationship using a new scale with negatively worded items. One goal of the current study is to extend their line of research to empirically test the relationship between efficacy and engagement.

\section{The Goals of the Present Study}

As mentioned earlier, work and organizational engagement are related, but separate constructs. Earlier findings have shown that work engagement can vary significantly from organizational engagement, meaning that high work engagement is not necessarily indicative of high organizational engagement. Due to limited evidence, it is 
not yet known if work engagement is generally higher than organizational engagement. One goal of the present study is to evaluate whether or not work engagement will be higher than organizational engagement in the current sample. Specifically:

H1: Employees will report higher work engagement when compared with organizational engagement.

Previous findings have also shown that different antecedents influence work and organizational engagement: job and organizational variables predict both work engagement and organizational engagement. However, work engagement is predicted by job characteristics and perceived organizational support while organizational engagement is predicted by perceptions of organizational support and procedural justice. What is not known is how the engagement dynamic is influenced by the personal characteristics of employees. The current study will extend the line of research by examining how the combination of job and organizational factors along with personal characteristics predict both work and organizational engagement. The personal characteristics incorporated into the model are established predictors of the opposing state of burnout. Therefore, if hardiness and self-efficacy are personality predictors of burnout, it is expected that they will add predictive value to the engagement model. The study test the following hypotheses:

H2: After controlling for work characteristics (perceived organizational support, job characteristics, and procedural justice) personality characteristics (psychological hardiness and self efficacy) will add significant predictive value to work engagement. 
H3: After controlling for work characteristics (perceived organizational support, job characteristics, and procedural justice) personality characteristics (psychological hardiness and self efficacy) will also add significant predictive value to organizational engagement.

\section{Method}

\section{Participants}

A total of 185 students from a large state university in Northern California participated in the study. However, data from 23 respondents were eliminated due to the insufficient completion of the survey. Thus the final sample consisted of 162 respondents. Fifty four percent of participants were male. Most of the participants were enrolled in upper division undergraduate Business courses. One third of the participants were enrolled in graduate Business courses. Participants' ages ranged from 20 to 50 years with an average age of $26(\mathrm{SD}=6.30)$. Fifty seven percent of the participants indicated that they had completed high school and some college, while $27 \%$ indicated that they held a Bachelor's degree. Four percent indicated they held Master's degrees. The remainder reported a combination of degrees and professional certificates. Participants' educational background is summarized in Table 1. Participants reported working at least half-time (20 hours/week) in their current job and worked in a variety of jobs (e.g., sales clerks, food service workers, administrative assistants, financial analyst) and in various industries (e.g, food service, sales, education, IT). The average number of hours worked per week was $33(\mathrm{SD}=9.67)$. 
Table 1.

Highest Educational Level Reported by Participants $(N=162)$

Response Choice

$\%$

Completed high school and some college

Hold bachelor's degree and completed some graduate courses

Completed high school with professional certificate

Hold bachelor's degree

Hold master's degree or higher

Hold master's degree with professional certificate/license

Hold bachelor's degree with professional certification/license

No response 


\section{Measures}

For the seven study measure scales, participants indicated the extent to which they agreed with each item using five point anchors ranging from "strongly disagree" (1) to "strongly agree" (5).

Perceived organizational support. POS was measured by the eight item short form of the Survey of Perceived Organizational Support (SPOS) (Rhoades et al., 2001). A sample item from the SPOS is "My organization really cares about my well-being" ( $\alpha$ $=.89)$.

Job characteristics. Job characteristics were measured by seven items developed by Hackman and Oldham (1980) with each item corresponding to a core job characteristic: autonomy, task identity, skill variety, task significance, feedback from supervisor, feedback from coworkers, and feedback from the job. A sample item is "how much autonomy is there in your job" $(\alpha=.62)$.

Procedural justice. Procedural justice was measured by seven items developed by Moorman (1991). A sample item for procedural justice is "My company follows formal decision making procedures to collect accurate information necessary for making decisions" $(\alpha=.90)$.

Psychological hardiness. Psychological hardiness was measured by the 15 item short form of the Dispositional Resilience Scale (DRS15-R) (Bartone, 2007). It has three underlying dimensions: Commitment, Control and Challenge. Each is measured with five items. A sample item for Commitment is "Most of my life gets spent doing things that are meaningful." A sample item for Control is "Planning ahead can help avoid most 
future problems." A sample item for Challenge is "Changes in routine are interesting to me" $(\alpha$ Overall $=.68 ; \alpha$ Commitment $=.59 ; \alpha$ Control $=.57 ; \alpha$ Challenge $=.70)$.

Self efficacy. Self efficacy was measured by the 10 item Personal Efficacy Beliefs Scale by Riggs, Warka, Babasa, Betancourt, and Hooker (1994). A sample item for self efficacy is "I am very proud of my job skills and abilities" $(\alpha=.75)$.

Work engagement. Work engagement was measured by the nine item short form of the Utrecht Work Engagement Scale (UWES) by Schaufeli et al. (2006). It has three underlying dimensions: Vigor, Dedication, and Absorption. Each is measured with three items. A sample item for Vigor is "At my job I feel strong and vigorous." For Dedication, a sample item is "I am enthusiastic about my job." For Absorption, a sample item is "I get carried away when I'm working" $(\alpha$ Overall $=.85 ; \alpha$ Vigor $=.76 ; \alpha$ Dedication $=.81 ; \alpha$ Absorption $=.60)$.

Organizational engagement. Organizational engagement was measured by a six item scale developed by Saks (2006). A sample item is "Being a member of this organization is very captivating" $(\alpha=.87)$.

Demographic information. Participants also answered demographic questions such as age, gender, educational level, average number of hours worked per week, and were asked to give a brief description of their occupation, occupational family, and industry. Items for all scales used in the study are listed in the Appendix.

\section{Procedure}

The researcher contacted Business faculty at the participating university, explained the purpose of the study, and asked for their permission to collect data from 
their classes on dates and times of their choosing. Interested faculty invited the researcher to their classrooms to collect data during the first 15 minutes of each scheduled class. The researcher gave the students a verbal explanation of the topic and the purposes of the study by stating that the study was about the prediction of work and organizational engagement. The researcher also read the students the cover letter that informed them that their participation was voluntary, anonymous, and confidential. The cover letter also listed the contact information for both the researcher and the sponsoring institutional entity, in the event that participants had questions or concerns about the study. Interested volunteers who indicated that they were employed were given the survey instrument and a copy of the cover letter to tear off and keep. They completed the survey and returned it by hand when finished.

Upon completion, the researcher gave participants further clarification about the specific research hypotheses, invited questions, and encouraged participants to contact the researcher if they had further questions. The researcher compiled all surveys into a sealed envelope and numbered them for tracking purposes at the point of data entry. Surveys that were less than half completed or were missing responses to the employment questions were excluded from further analyses.

Results

\section{Descriptive Statistics}

Among the work characteristic variables (perceived organizational support, job characteristics, and procedural justice), participants reported the highest rating for job characteristics $(M=3.62, S D=.60)$, followed by perceived organizational support $(M=$ 
$3.44, S D=.79)$ and procedural justice $(M=3.32, S D=.80)$. Of the personal characteristics, participants scored higher in self efficacy $(M=3.95, S D=.50)$ than in overall hardiness $(M=3.71, S D=.39)$. On the hardiness scales, participants scored highest on control $(M=4.03, S D=.54)$. The lowest score was reported for challenge ( $M$ $=3.49, S D=.65$ ). Of the work engagement measures, the highest score was reported for dedication $(M=3.58, S D=.84)$ and the lowest score was reported for vigor $(M=3.25$, $S D=.84)$. Participants also reported higher overall work engagement $(M=3.45$, $S D=.66)$ than organizational engagement $(M=3.12, \mathrm{SD}=.81)$. Table 2 presents the means and standard deviations for the study variables.

Correlations Among the Measured Variables

Table 3 presents correlations among the study variables. The work characteristic variables had significant bivariate correlations with overall work engagement. Overall work engagement was significantly related to POS $(r=.51, p$ $<.001)$, job characteristics $(r=.50, p<.001)$, and procedural justice $(r=.42, p$ $<.001)$. One of the two personal characteristics variables, psychological hardiness, also significantly correlated with overall work engagement $(r=.38, p<.001)$. However, self efficacy was not significantly correlated with overall work engagement $(r=.10, p=.23)$. Of the three hardiness dimensions (commitment, control, and challenge), commitment had the strongest relationship with overall work engagement $(r=.60, p<.001)$. Among the engagement dimensions, commitment had the strongest relationship with vigor ( $r=$ $.59, p<.001)$, followed by dedication $(r=.53, p<.001)$ and absorption $(r=.41, p<.001)$. 
Table 2

Descriptive Statistics for Work and Organizational Engagement

\begin{tabular}{|c|c|c|c|}
\hline Variable & $\mathrm{n}$ & M & SD \\
\hline Perceived organizational support & 157 & 3.44 & .79 \\
\hline Job characteristics & 158 & 3.62 & .60 \\
\hline Procedural justice & 158 & 3.32 & .80 \\
\hline Overall hardiness & 161 & 3.71 & .39 \\
\hline Hardy commitment & 161 & 3.61 & .58 \\
\hline Hardy control & 162 & 4.03 & .54 \\
\hline Hardy challenge & 162 & 3.49 & .65 \\
\hline Self efficacy & 158 & 3.95 & .50 \\
\hline Overall work engagement. & 161 & 3.45 & .66 \\
\hline Engagement vigor & 162 & 3.25 & .84 \\
\hline Engagement dedication & 162 & 3.58 & .84 \\
\hline Engagement absorption & 162 & 3.49 & .69 \\
\hline Organizational engagement & 159 & 3.12 & .81 \\
\hline
\end{tabular}


Table 3

Correlations Among the Measured Variables

\begin{tabular}{|c|c|c|c|c|c|c|c|c|c|c|c|c|}
\hline & 1 & 2 & 3 & 4 & 5 & 6 & 7 & 8 & 9 & 10 & 11 & 12 \\
\hline \multicolumn{13}{|l|}{$\begin{array}{l}\text { 1. Perceived organizational } \\
\text { support }\end{array}$} \\
\hline 2. Job characteristics & $.45^{* *}$ & & & & & & & & & & & \\
\hline 3. Procedural justice & $.58 * *$ & $.51 * *$ & & & & & & & & & & \\
\hline 4. Overall hardiness & $.23 * *$ & $.30 * *$ & $.19^{*}$ & & & & & & & & & \\
\hline 5. Hardy- commitment & $.40 * *$ & $.32 * *$ & $.25^{* *}$ & $.73 * *$ & & & & & & & & \\
\hline 6. Hardy- control & $.18^{*}$ & $.31 * *$ & $.22 * *$ & $.64 * *$ & $.32 * *$ & & & & & & & \\
\hline 7. Hardy-challenge & -.08 & -.01 & -.07 & $.65^{* *}$ & $.17 *$ & .04 & & & & & & \\
\hline 8. Self efficacy & .01 & .09 & -.04 & $.31 * *$ & $.18^{*}$ & $.19^{*}$ & $.25 * *$ & & & & & \\
\hline $\begin{array}{l}\text { 9. Overall work } \\
\text { engagement }\end{array}$ & $.51 * *$ & $.50 * *$ & $.42 * *$ & $.38 * *$ & $.60 * *$ & .11 & .06 & .10 & & & & \\
\hline 10. Engagement- vigor & $.43 * *$ & $.43^{* *}$ & $.44 * *$ & $.38 * *$ & $.58 * *$ & .05 & .12 & .10 & $.85^{* *}$ & & & \\
\hline 11. Engagement- dedication & $.48 * *$ & $.49 * *$ & $.35 * *$ & $.29 * *$ & $.53 * *$ & .08 & -.02 & .08 & $.89 * *$ & $.66 * *$ & & \\
\hline 12. Engagement- absorption & $.36 * *$ & $.38 * *$ & $.27 * *$ & $.30 * *$ & $.41 * *$ & $.21 * *$ & .01 & .06 & $.79 * *$ & $.47 * *$ & $.60 * *$ & \\
\hline $\begin{array}{l}\text { 13. Total organizational } \\
\text { engagement }\end{array}$ & $.64 * *$ & $.42 * *$ & $.51 * *$ & $.29 * *$ & $.51 * *$ & .07 & .02 & .05 & $.72 * *$ & $.64 * *$ & $.69 * *$ & $.47 * *$ \\
\hline
\end{tabular}

$* *$ indicates $\mathrm{p}<.001$, one tailed; *indicates $\mathrm{p}<.05$, two tailed 
Control and challenge were not significantly related to overall work engagement (control, $r=.11, p=.15$; challenge, $r=.06, p=.46$ ). However, control was significantly related to the absorption dimension $(r=.21, p=<.05)$, but not with either dedication $(r=$ $.08, p=.30)$ or vigor $(r=.05, p=.54)$. Challenge was also not significantly related to overall work engagement ( $r=.06, p=.46$ ), nor was it related to any of its dimensions: vigor $(r=.12, p=.12)$, absorption $(r=0.01, \mathrm{p}=.87)$, and dedication $(r=-.02, p=.83)$.

The work characteristic variables also had significant bivariate correlations with organizational engagement: $\operatorname{POS}(r=.64, p<.001)$, procedural justice $(r=.51, p<.001)$, and job characteristics $(r=.42, p<.001)$. Similarly with work engagement, overall hardiness was significantly related to organizational engagement $(r=.29, p<.001)$. As with overall work engagement, organizational engagement was significantly related to commitment $(r=.51, p<.001)$. However, neither control $(r=.07, p=.38)$ nor challenge $(r=.20, p=.84)$ was significantly related to organizational engagement. Self efficacy and organizational engagement were not significantly related either $(r=.05, p=.54)$.

With regard to self efficacy, while it was not directly related with either engagement variable, it was significantly correlated with overall hardiness $(r=.31, p$ $<.001)$. Of the three hardiness dimensions, it had the strongest relationship with challenge $(r=.25, p<.001)$, followed by control $(r=.19, p<.05)$ and commitment $(r=$ $.18, p<.05)$. Tests of Hypotheses

Hypothesis 1 predicted that work engagement would be higher than organizational engagement. Consistent with the hypothesis, participants reported higher 
overall work engagement $(M=3.45)$ than organizational engagement $(M=3.12)$. While the two measures were highly correlated with each other $(r=.72, p<.001)$, results of a two-tailed paired t-test showed a significant difference in the means, $t(157)=7.15, p$ $<.001$. Therefore Hypothesis 1 was supported.

Hypothesis 2 stated that personal characteristics would predict work engagement after controlling for work characteristics. To test the hypothesis, a hierarchical regression analysis was performed with work characteristics (POS, job characteristics, and procedural justice) entered in step 1 and personal characteristics (psychological hardiness and self efficacy) entered in step 2. As can be seen at the left side of Table 4, results showed that work characteristics accounted for $35 \%$ of the variance in work engagement, $R^{2}=.35, F_{-}(3,142)=25.89, p<.001$. The beta values at step 1 showed that work engagement was best predicted by job characteristics $(\beta=.35, p<.001)$, closely followed by POS $(\beta=.28, p=.002)$. Procedural justice did not emerge as a significant predictor ( $\beta$ $=.09, p=.31$.

At step 2, 40\% of variance in work engagement was accounted for, and the personal characteristics added significant predictive value to the model, $R^{2}=.40, F(5$, $140)=18.50, p<.001, \mathrm{R}^{2}$ change $=.04, F$ change $(2,140)=5.15, p<.05$. At step 2 , work engagement was best predicted by overall hardiness $(\beta=.23, p<.05)$. Self efficacy did not have a significant beta $(\beta=.-.00, p=.95)$. 
Table 4

Prediction of Overall Work Engagement by Work and Personal Characteristics

Analysis 1

(At Step 2, Overall Hardiness evaluated as one dimension)
Analysis 2

(At Step 2, Hardiness evaluated as its three dimensions)

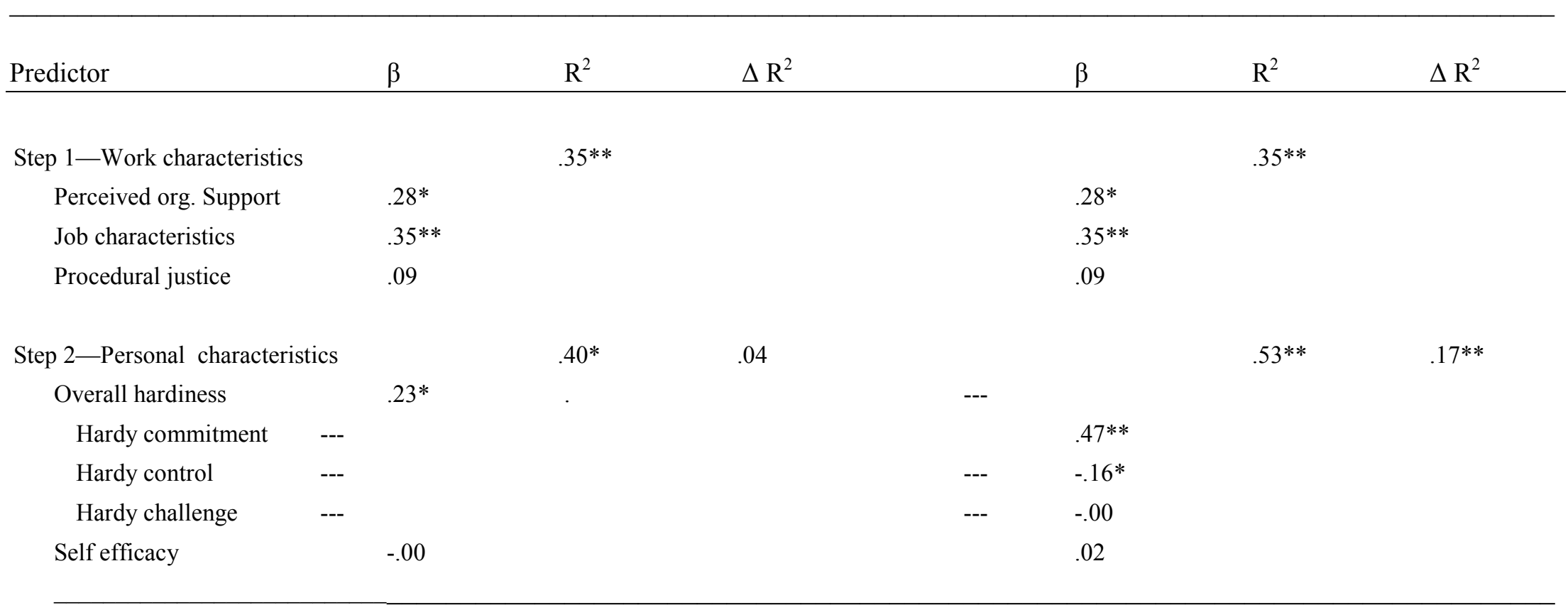

$* *_{\text {indicates }} \mathrm{p}<.001 ; *$ indicates $\mathrm{p}<.05$ 
Because there were three underlying dimensions of hardiness with varying bivariate correlations with work engagement, a second hierarchical regression analysis was conducted with the same step 1 variables and the three individual hardiness measures and self efficacy at step 2. Again, step 1 accounted for $35 \%$ of the variance in overall work engagement (see previous analysis ).

At step 2, 53\% of total variance was accounted for. This change in variance was significant, $R^{2}=.53, F(7,138)=22.04, p<001, R^{2}$ change $=.17, F$ change $(4,138)=$ $12.74, p<.001$. At step 2 work engagement was best predicted by commitment $(\beta=.47$, $p<001)$. Control also had a significant beta value $(\beta=.-16, p<05)$, however, this variable emerged as a suppressor (Cohen \& Cohen, 1983). This conclusion was made for two reasons. First, control had a negative beta value, yet it had a positive but non significant relationship with work engagement $(r=.11, p=.15)$. Second, control was significantly related to commitment $(r=.32, p<.001)$ and commitment was significantly related to work engagement $(r=.60, p<.001)$.

Based on these relationships, control was more related to the shared variance with commitment than with the variance in work engagement, so it did not add predictive value. Neither challenge nor self efficacy added predictive value in step 2 (challenge: $\beta=$ $.01, p=.92$; self efficacy: $\beta=.02, p=.73$ ). Table 4 presents the results of the prediction of overall work engagement with hardiness evaluated as one dimension and those with hardness with its component dimensions. 
Based on these analyses, overall psychological hardiness added significant predictive value to work engagement after controlling for work characteristics. Self efficacy did not add predictive value. Therefore, Hypothesis 2 was partially supported. More variance was accounted for when hardiness was broken up into its component dimensions (commitment, control, and challenge). Based on the evaluation of the betas, it appears that commitment is the single hardiness variable that adds predictive value to work engagement.

Hypothesis 3 stated that personal characteristics would predict organizational engagement after controlling for work characteristics. To test this hypothesis, a hierarchical regression analysis was performed. Work characteristics were entered in step 1 and personal characteristics were entered in step 2. Work characteristics accounted for $44 \%$ of the variance in organizational engagement, $R^{2}=.44 F(3,141)=37.57, p$ $<.001$. At step 1, organizational engagement was best predicted by $\operatorname{POS}(\beta=.46, p<.001)$ and procedural justice $(\beta=.18, p=.025)$.

At step 2, 46\% of total variance in organizational engagement was accounted for, but personal characteristics in step 2 did not add predictive value: $R^{2}=.46, F(5,139)=$ $23.64, p<.001, R^{2}$ change $=.02, F$ change $(2,139)=1.96, p=.14$.

As with work engagement, the hardiness dimensions had differing bivariate relationships with organizational engagement. A second hierarchical regression analysis was conducted with the same step 1 variables, and the three hardiness dimensions and self efficacy in step 2. Again, step 1 accounted for $44 \%$ of the variance in overall work engagement (see previous analysis). 
At step 2, 54\% of total variance was accounted for and the change in the variance was significant, $R^{2}=.54, F(7,137)=22.54, p<001, R^{2}$ change $=.09, F_{-}$change $(4,137)$ $=6.70 p<.001$. As with work engagement, at step 2 organizational engagement was best predicted by commitment $(\beta=.33, p<001)$. Control also had a significant beta value ( $\beta$ $=.-17, p<05$ ), however, this variable also emerged as a suppressor as it did with work engagement. Control had a negative beta value, yet a positive but non significant relationship with organizational engagement $(r=.07, p=.38)$. Also, control was significantly related to commitment $(r=.32, p<.001)$ and commitment was significantly related to organizational engagement $(r=.51, p<.001)$. Based on these relationships control was more related to the shared variance with commitment than with the variance in organizational engagement, so it did not add predictive value. Neither challenge nor self efficacy added predictive value at step 2 (challenge: $\beta=.02, p=.73$; self efficacy: $\beta$ $=.01, p=.87$ ). Table 5 presents the results of the prediction of organizational engagement with hardiness evaluated as one dimension and those with hardness with its component dimensions.

Based on these analyses, after controlling for work characteristics, self efficacy added no predictive value to organizational engagement. Psychological hardiness added significant predictive value only when it was broken up into its component dimensions (commitment, control, and challenge). 
Table 5

Prediction of Organizational Engagement by Work and Personal Characteristics

Analysis 1

(At Step 2, Overall Hardiness evaluated as one dimension)
Analysis 2

(At Step 2, Hardiness evaluated as its three dimensions)

\begin{tabular}{|c|c|c|c|c|c|c|}
\hline Predictor & $\beta$ & $\mathrm{R}^{2}$ & $\Delta \mathrm{R}^{2}$ & $\beta$ & $\mathrm{R}^{2}$ & $\Delta \mathrm{R}^{2}$ \\
\hline Step 1-Work characteristics & & $.44 * *$ & & & $.44 * *$ & \\
\hline Perceived org. Support & $.46^{* *}$ & & & $.46^{* *}$ & & \\
\hline Job characteristics & .13 & & & .13 & & \\
\hline Procedural justice & $.18^{*}$ & & & .18 & & \\
\hline Step 2-Personal characteristics & & .46 & .02 & & $.54 * *$ & $.09^{* *}$ \\
\hline Overall hardiness & .13 & & & --- & & \\
\hline Hardy commitment & --- & & & $.33^{* *}$ & & \\
\hline Hardy control & --- & & & $-.17 *$ & & \\
\hline Hardy challenge & --- & & & .02 & & \\
\hline Self efficacy & -.00 & & & .01 & & \\
\hline
\end{tabular}

**indicates $\mathrm{p}<.001 ; *$ indicates $\mathrm{p}<.05$, 
Based on the evaluation of the betas, it appears that commitment was the single hardiness dimension that adds predictive value to organizational engagement and to work engagement. These results show that Hypothesis 3 was partially supported.

\section{Exploratory Analyses}

To explore whether or not the study variables predicted the engagement dimensions differently from overall work engagement, separate hierarchical regression analyses were conducted for vigor, dedication and absorption. For each analysis, work characteristics were entered as step 1, and personal characteristics were entered at step 2. As was done with overall work engagement, separate step 2 comparisons were done with hardiness evaluated as one dimension and hardness with its component dimensions.

Vigor. Work characteristics accounted for $29 \%$ of the variance in vigor, $R^{2}=.29$, $F(3,143)=19.65, p<.001$. The beta values at step 1 showed that vigor was best predicted by job characteristics $(\beta=.28, p<.001)$. Job characteristics were also the best predictor of overall work engagement. However, procedural justice and POS predicted vigor differently from overall work engagement. Procedural justice was significant in predicting vigor $(\beta=.22, p<.05)$ but not in predicting overall work engagement. While POS was the second highest beta for overall work engagement, it was not a significant predictor of vigor $(\beta=.16, p=.08)$.

At step 2,34\% of the variance in vigor was accounted for and the personal characteristics added significant predictive value, $R^{2}=.34, F(5,141)=14.56, p<.001$, $R^{2}$ change $=.04, F$ change $(2,140)=5.15, p<.05$. As with overall work engagement, at step 2 vigor was best predicted by overall hardiness $(\beta=.23, p<.05)$. Self efficacy did not 
have a significant beta $(\beta=-.00, p=.95)$.

When step 2 was reentered with hardiness as its component dimensions personal characteristics accounted for more variance in vigor than when hardiness was evaluated overall. While step 1 accounted for $29 \%$ of the variance (see previous analysis), $52 \%$ of the variance was accounted for at the new step $2, R^{2}=.52, F(7,139)=21.39, p<.001$, $R^{2}$ change $=.23, F$ change $(4,139)=16.37, p<.001$. At step 2 , vigor was best predicted by commitment $(\beta=.49, p<.001)$, same as it was for overall work engagement.

Control also had a significant beta $(\beta=-.26, p<.001)$, yet it emerged as a suppressor variable the same as it did with overall work engagement.. Neither challenge nor self efficacy added predictive value in step 2 (challenge: $\beta=.06, p=.35$; self efficacy: $\beta=.05, p=.52$ ).

Dedication. Work characteristics accounted for $31 \%$ of the variance in dedication, $R^{2}=.31, F(3,143)=21.75, p<.001$. The beta values at step 1 showed that work characteristics predicted dedication the same way as overall work engagement. Job characteristics had the highest beta $(\beta=.34, p<.001)$, closely followed by POS ( $\beta=.33, p$ $<.001)$ Procedural justice was not significant in predicting dedication $(\beta=-.03, p=.78)$. At step 2,34\% of the variance in vigor was accounted for and the personal characteristics added significant predictive value, $R^{2}=.34, F(5,141)=14.56, p<.001$, $R^{2}$ change $=.04, F$ change $(2,140)=5.15, p<.05$. As with overall work engagement, at step 2 vigor was best predicted by overall hardiness $(\beta=.23, p<.05)$.

Self efficacy did not have a significant beta $(\beta=-.00, p=.95)$.

When step 2 was reentered with hardiness as its component dimensions personal 
characteristics accounted for more variance in dedication than when hardiness was evaluated overall. While step 1 accounted for $31 \%$ of the variance (see previous analysis), $45 \%$ of the variance was accounted for at the new step $2, R^{2}=.45, F(7,139)=$ $16.21, p<.001, R^{2}$ change $=.14, F$ change $(4,139)=8.59, p<.001$. At step 2 , dedication was best predicted by commitment $(\beta=.41, p<.001)$, same as it was for overall work engagement and vigor.

Although control also had a significant beta $(\beta=-.19, p<.001)$, it emerged as a suppressor variable the same as it did with overall work engagement and vigor. Neither challenge nor self efficacy added predictive value in step 2 (challenge: $\beta=-.07, p=.27$; self efficacy: $\beta=.03, p=.70$ ).

Absorption. Work characteristics accounted for $19 \%$ of the variance in absorption, $R^{2}=.19, F(3,143)=10.98, p<.001$. The beta values at step 1 showed work characteristics predicted absorption the same way as overall work engagement and dedication. Job characteristics had the highest beta $(\beta=.28, p<.05)$, closely followed by POS $(\beta=.21, p<.05)$ Procedural justice was not significant in predicting absorption $(\beta=-$ $.01, p=.95)$.

At step 2, 23\% of the variance in absorption was accounted for and the personal characteristics added significant predictive value, $R^{2}=.23, F(5,141)=8.51, p<.001, R^{2}$ change $=.05, F$ change $(2,141)=4.09, p<.05$. As with overall work engagement and vigor, at step 2 absorption was best predicted by overall hardiness $(\beta=.24, p<.05)$. Self efficacy did not have a significant beta $(\beta=-.04, p=.63)$.

When step 2 was reentered with hardiness as its component dimensions personal 
characteristics accounted for more variance in absorption. While step 1 accounted for $19 \%$ of the variance (see previous analysis), $26 \%$ of the variance was accounted for at the new step $2, R^{2}=.26, F(7,139)=7.11, p<.001, R^{2}$ change $=.08, F$ change $(4,139)=$ $3.60, p<.05$. At step 2 , absorption was best predicted by commitment $(\beta=.27, p<.05)$, same as it was for overall work engagement, vigor, and dedication. Control, challenge, and self efficacy did not add predictive value at the new step 2 (control: $\beta=.10, p=.22$; challenge: $\beta=-.02, p=.81$; self efficacy: $\beta=-.02, p=.77)$.

In summary, the job characteristics variable was the leading work characteristic in predicting overall work engagement and each of its dimensions. Perceived organizational support was the next leading predictor of overall work engagement, dedication, and absorption. Vigor was predicted differently by work characteristics: procedural justice was a significant predictor of vigor but POS was not significant. Commitment added equal predictive value to work engagement and each of its dimensions. The comparisons of the betas for overall work engagement and each of its dimensions is summarized in Table 6.

\section{Discussion}

The first study goal was to evaluate differences between work engagement and organizational engagement. Earlier findings by Saks (2006) have shown that work engagement is somewhat independent of organizational engagement, meaning that high work engagement is not necessarily indicative of high organizational engagement. 
Table 6

Beta Weights for Work Engagement Overall and for Each Dimension

\begin{tabular}{|c|c|c|c|}
\hline Overall & & & \\
\hline $\begin{array}{l}\text { Work } \\
\text { Engagement }\end{array}$ & -vigor & $\begin{array}{l}\text { Engagement- } \\
\text { dedication }\end{array}$ & $\begin{array}{l}\text { Engagement- } \\
\text { absorption }\end{array}$ \\
\hline
\end{tabular}

Predictor

Step 1-Work characteristics

$\beta$

$\begin{array}{lcccc}\text { Perceived org. support } & .28^{*} & .16 & .33^{* *} & .21^{*} \\ \text { Job characteristics } & .35^{* *} & .28^{* *} & .34 * * & .28^{*} \\ \text { Procedural justice } & .09 & .22 * & -.03 & .01\end{array}$

Step 2-Personal characteristics

$\begin{array}{lcccc}\text { Overall hardiness } & .23 * & .23 * & .12 & .24 * \\ \text { Hardy commitment } & .47 * * & .49 * * & .41 * * & .27 * \\ \text { Hardy control } & -.16 & -.26^{* *} & -.19 * & .10 \\ \text { Hardy challenge } & -.00 & .06 & -.07 & -.02 \\ \text { Self efficacy } & .02 & .05 & .03 & -.02\end{array}$

$* *$ indicates $\mathrm{p}<.001 ; *$ indicates $\mathrm{p}<.05$ 
The first hypothesis evaluated whether or not work engagement scores are higher than organizational engagement scores. Consistent with Saks, the present study found that participants reported significantly higher work engagement than organizational engagement. One possible explanation for these findings could be due to the fact that participants scored higher on absorption (one of the work engagement dimensions) than they did on organizational engagement. Absorption refers to the intensity of focus on one's role (Goffman, 1961; Kahn, 1990). When people are absorbed in their work, they are more readily able to ignore distractions from the work place (Rothbard, 2001). Also, respondents rated higher on dedication than absorption. Perhaps, it is easier to be engaged in one's work than engaged in one's organization given that individuals have more control over one's work than over one's organization.

The second goal of the study was to extend the predictability of work engagement (Hypothesis 2) and organizational engagement (Hypothesis 3 ) by adding personality variables after controlling for work characteristics. The present study examined two personality variables: psychological hardiness and self efficacy.

Hypotheses 2 and 3 were partially supported. Self efficacy did not add predictive value to either form of engagement after controlling for work characteristics. Work engagement was predicted by overall hardiness after work characteristics were taken into account. However, more variance was accounted for when hardiness was broken up into its component dimensions: commitment, control, and challenge. Upon evaluation of the findings, commitment appeared to be the only dimension of hardiness that added predictive value to work engagement. 
Similarly with work engagement, organizational engagement was also predicted by commitment when work characteristics were taken into account. When evaluated as one dimension, hardiness did not add predictive value after controlling for work characteristics.

Exploratory analyses were also conducted to determine whether or not the study variables would predict the engagement dimensions differently from overall work engagement. Findings show that job characteristics was the leading work characteristic variable in predicting overall work engagement and each of its dimensions. Perceived organizational support was the next leading predictor of overall work engagement, dedication, and absorption. Vigor was predicted differently by work characteristics: procedural justice was a significant predictor of vigor but POS was not significant. Commitment added predictive value to both overall engagement and each of its dimensions.

In summary, findings of the study demonstrate that participants experience higher work engagement relative to organizational engagement. Findings also show that the commitment aspect of psychological hardiness predicts both work and organizational engagement after controlling for work characteristics. Although commitment predicts both forms of engagement, it adds greater predictive value to work engagement relative to organizational engagement. The study did not find evidence that self efficacy added predictive value to either form of engagement. Given that participants scored higher in self efficacy than they did on the commitment measure, it is possible that engagement is 
more strongly tied to a person's intrinsic motivation than to his or her capability of success.

Study Implications

Following Saks (2006), the current study also examined engagement separately with respect to work and organization. Saks' earlier findings showed that the two constructs were related but distinct. While they share the common antecedent of perceived organizational support, they are influenced differently by other factors. Saks found that job characteristics were the strongest predictor of work engagement when compared with POS and procedural justice. Consistent with Saks, the present study also found that job characteristics and POS predicted overall work engagement and that POS and procedural justice predicted organizational engagement.

However, the study also found that work characteristics have differing influences on each dimension of engagement. While overall work engagement, dedication, and absorption were predicted by job characteristics and POS, procedural justice was important in predicting vigor, yet POS was not. Given these findings, it would appear that there is empirical value to studying engagement based on its dimensions versus overall.

Also, the present study is the first to retest Saks's earlier findings that work engagement is higher than organizational engagement. Saks conducted his study among Canadian workers, while the present study was conducted in the United States. By reevaluating this comparison, the study provides further empirical support that there is value in evaluating these two forms of engagement separately. 
The present study also makes a contribution to the engagement literature by extending the predictability of work and organizational engagement by incorporating both work and personal characteristics. To this point, it was unclear whether or not engagement was driven purely by work characteristics or if it was partly related to the personal traits of individual employees. Saks and others (Freeney \& Tiernan, 2006) stressed the importance of exploring this question to further the understanding of what drives both work and organizational engagement. The study was the first to show that the commitment aspect of psychological hardiness relates to both work and organizational engagement even after factoring in work characteristics.

When examining studies of psychological hardiness and burnout, it is not surprising that hardiness was found to predict engagement. The current study shows commitment drives engagement in the same manner as burnout: hardiness was associated with emotional exhaustion on the burnout dimension, and in this study commitment was most highly correlated with vigor on the engagement dimension. These findings show that the tendency to find meaning in activities through a sense of involvement drives one to fulfill work obligations, thus perpetuating feelings of engagement.

In studies of high burnout professions such as teaching and nursing, burnout was consistently related to low scores of hardiness. Among teachers, positive hardiness has been linked to increased feelings of personal accomplishment (Lopez et al., 2008; Chan et al., 2003) Among nurses, Duquette et al. (1995) found that low hardiness and work stressors were the most important predictors of burnout. Other findings by Constantini et al. (1997) demonstrated that high psychological hardiness scores were associated with 
lower emotional exhaustion and increased personal accomplishment. The authors went on to suggest that screening of personality traits could be useful in preventing burnout among critical care nurses.

Burnout studies have also found evidence that commitment—-the tendency to find meaning and purpose in activities through a sense of involvement-is the key driver in the hardiness-burnout relationship. Topf (1989) found that overall hardiness predicted burnout among nurses but commitment by itself accounted for most of the variance in the model. Holt, Fine, and Tollefson (1987) observed the same findings in the study of teacher burnout. Based on the results of the present study and findings on burnout, the commitment dimension of hardiness appears to play an important role for the prediction of engagement as well as that of burnout.

The study did not find that self efficacy adds predictive value to either engagement model. Given that study participants scored higher in self efficacy than they did on commitment, it would appear that engagement is more associated with self motivation than with self efficacy.

Since high engagement predicts low turnover (Harter, Schmidt, \& Keyes, 2003), the findings of the present study also have practical implications for organizations. It is most noteworthy that the present study was conducted during a depressed economic climate, during which national unemployment was estimated at 9.7 percent and regional unemployment was estimated at 9.5 percent, according to August 2009 data from the San Francisco Center for Economic Development. The participants surveyed reported being less engaged with their employers than with their work itself. This finding is especially 
timely as organizations are now evaluating how to prevent turnover when the economy improves.

Post recession turnover intentions were the subject of a study by Deloitte Consulting (2009). While the study was not specific to engagement, it found that more employees intended to leave their jobs post recession than upper management had anticipated. In a global survey of 368 employees at large organizations (defined as revenues in excess of US $\$ 500$ million), almost half of the employees surveyed in August 2009 were either looking for a job or planned to look when the recession ends. Generation X workers (workers born between 1965 and 1980) reported the highest turnover intentions. Only $37 \%$ percent of Generation $\mathrm{X}$ respondents indicated they would stay with their current employers post recession. However, only nine percent of corporate leaders surveyed earlier in the year (May) reported that they expected turnover to increase among this population group in the year after economic conditions improved. This finding shows that many employers are not aware of the intentions of their employees. If these employers do not invest in survey tools to poll their employees, it is unlikely they will be able to design retention strategies that will tap into factors of intrinsic motivation such as engagement.

Research by Hewitt Associates (2009) shows that Canadian employers are making an investment into evaluating engagement and designing targeted interventions to increase it. Hewitt found that the number of participating organizations in the 2009 "Best Employers in Canada" survey doubled from the previous year. Based on a decade's worth of longitudinal data, findings have shown that high engagement yields low 
turnover and less absenteeism. According to a study leader Neil Crawford, "the current economic environment has sparked increased interest in the study and the role of employee engagement in successfully addressing challenging times" (para. 2). These findings suggest that organizations that invest in maintaining an engaged workforce will have greater sustainability even as turnover increases post recession.

The understanding of how personal characteristics drive engagement also has practical value for organizations. As noted by Freeney and Tiernan (2006), intervention strategies aimed at the organization will not be effective if the situational factors cannot be evaluated along with the inherent personality traits of the employees. Intervention strategies will be most effective when organizations take advantage of assessment tools that measure work specific variables and utilize assessment tools that help their employees identify their personal strengths (Gallup offers the Strengths Finder assessment, for example). Empirical evidence that commitment drives work and organizational engagement will benefit organizations that wish to design meaningful interventions to encourage employees to capitalize on their personal strengths.

\section{Study Evaluation and Directions for Future Research}

One of strengths of this study was that it surveyed respondents from a wide variety of industries, so that the findings observed are less likely to be attributed to organizational culture or the influence of any dominant profession. The study also included a mix of full time and part time workers and it included workers from varying educational levels. 
One limitation of the study was that it was conducted with university students, the majority of which only worked part time for their employers. Because the participants were surveyed in their classrooms, it is possible that the work and organizational "engagement" they experienced at work cannot be measured in a school environment that shifts their attention to a different role. This dichotomous association between work life and school life is one possible explanation for some of the low reliabilities found in the measures, specifically the engagement dimension of absorption, job characteristics, commitment, and control. Many of these items tap situational factors that might not carry over into another environment. Future studies could evaluate the predictive model between full time and part time employees who are surveyed in the workplace itself. Another limitation of this study was that the majority of participants were in their 20's, with limited data available to make comparisons between age groups. Future studies could examine whether or not the same engagement factors examined in the current study would predict engagement among different age groups.

In summary, previous engagement research shows that job and organizational engagement are influenced by different factors. While perceived organizational support is important in predicting both types of engagement, job characteristics are the key predictor of work engagement. Organizational engagement is predicted mostly by perceived organizational support and followed by procedural justice. The current study extends the prediction models by exploring how the engagement dynamic is influenced by the personal characteristics of the employees once work characteristics are taken into account. The personal characteristics incorporated into the model—psychological 
hardiness and self efficacy_-were established predictors of the opposing state of burnout. Findings show that psychological hardiness, specifically commitment, adds significant predictive value to both work and organizational engagement after controlling for work characteristics. However, commitment accounts for more variance in work engagement when compared with organizational engagement. Although it was correlated with overall hardiness, self efficacy was not found to be directly related to either engagement type, nor did it contribute to the overall predictive value of either engagement type. Based on these findings, it would appear that the commitment drive is more crucial to engagement than perceived self efficacy. In other words, engagement is not about a worker thinking, "I can do it" solely based on skills assessment, but because of his or her commitment to the purpose at hand. 


\section{References}

Bakker, A. B., Schaufeli, W. B., Leiter, M. P., \& Taris, T. W. (2008). Work engagement: An emerging concept in occupational health psychology. Work \& Stress, 22, 187 200. doi: $10.1080 / 02678370802393649$

Bandura, A. (1986). Social foundations of thought and action: A social cognitive theory. Englewood Cliffs, NJ: Prentice-Hall.

Bartone, P. T. (2007). Test-Retest reliability of the dispositional resilience scale-15: A brief hardiness scale. Psychological Reports, 101, 943-944. doi: 10.2466?PRO.101.3943-944

Boyle, A., Crap, M .J., Younger, J. \& Thornby, D. (1991). Personality hardiness, ways of coping, social support and burnout in critical care nurses. Journal of Advanced Nursing 16, 850- 857.

Chan, D. W., (2003). Hardiness and its role in the stress-burnout relationship among prospective Chinese teachers in Hong Kong. Teaching and Teacher Education, 19, 381-395. doi:10.1016/S0742-051X(03)00023-4

Cohen, J., \& Cohen, P. (1983). Applied multiple regression/correlation analysis for the behavioral sciences. New York, NY: Lawrence Erlbaum Associates.

Colquitt, J. A. (2001). On the dimensionality of organizational justice: A construct validation of a measure. Journal of Applied Psychology, 86, 386-400. doi: 10.1037/0021-9010.86.3.386 
Constantini, A., Solano, L., DiNapoli, R., \& Bosco, A, (1997). Relationship between hardiness and risk of burnout in a sample of 92 nurses working in oncology and AIDS wards. Psychotherapy and Psychosomatics, 66, 78-82.

Deci, E. L., Connell, J. P., \& Ryan, R. M. (1989). Self-determination in a work organization. Journal of Applied Psychology, 74, 580-590. doi: 10.1037/00219010.74 .4 .580

Deci, E. L., \& Ryan, R. M. (1987). The support of autonomy and the control of behavior. Journal of Personality and Social Psychology, 53, 1024-1037.

Deloitte. (2009). Managing talent in a turbulent economy keeping your team intact. [White paper]. Retrieved from http://www.deloitte.com/assets/DcomUnitedStates/Local\%20Assets/Documents/us_talent_RetentionReport_091609.pdf

Duquette, A., Kerouac, S., Sandhu, B. K., Ducharme, F., \& Saulnier, P. (1995). Psychosocial determinants of burnout in geriatric nursing. International Journal of Nursing Studies, 32, 443-456

Edmondson, A. (1996). Learning from mistakes is easier said than done: Group and organizational influences on the detection and correction of human error. Journal of Applied Behavioral Science, 32, 5-32. doi: 10.1177/0021886396321001

Edmondson, A. (1999). Psychological safety and learning behavior in work teams. Administrative Science Quarterly, 44, 350-383. doi: 10.2307/2666999

Fowler, K. L. (2006). The relations between personality characteristics, work environment, and the professional well-being of music therapists. Journal of Music Therapy, XLIII, 174-197. 
Freeney, Y., \& Tiernan, J. (2006). Employee engagement: An overview of the literature on the proposed antithesis to burnout. Irish Journal of Psychology, 27, 130-141.

Goffman, E. (1961). Encounters: Two studies in the sociology of interaction. Indianapolis, IN: Bobbs-Merrill.

Hackman, J. R., \& Oldham, G. R. (1980). Work redesign. Reading, MA: AddisonWesley.

Harter, J. K., Schmidt, F. L., \& Keyes, C. L. M. (2003). Well-being in the workplace and its relationship to business outcomes: A review of the Gallup Studies. In C. L .M. Keyes \& J Haidt (Eds.) Flourishing positive psychology and the life well lived (pp. 205-224). Washington, DC: American Psychological Association.

Holbeche, L., \& Springett, N. (2004). In search of meaning in the workplace. UK: Roffey Park Institute.

Holt, P., Fine, M. J., \& Tollefson, N. (1987). Mediating stress: Survival of the hardy. Psychology in the Schools, 24, 51-58.

Kahn, W. A. (1990). Psychological conditions of personal engagement and disengagement at work. Academy of Management Journal, 33, 692-724. doi: $10.2307 / 256287$

Keane. A., Ducette, J., \& Adler, D. C. (1985). Stress in ICU and non ICU nurses. Nursing Research, 34, 231-236.

Kobasa, S. C. (1979) Stressful life events, personality, and health: An inquiry into hardiness. Journal of Personality and Social Psychology, 37, 1-11. 
Kobasa, S. C., Maddi, S. R., \& Kahn, S. (1982). Hardiness and health: A prospective study. Journal of Personality and Social Psychology, 42, 168-177.

Koeske, G. F., \& Koeske, R. D. (1989). Construct validity of the Maslach Burnout Inventory: A critical review and re-conceptualization. Journal of Applied Behavioral Sciences , 25, 131-132. doi: 10.1177/0021886389252004

Leiter, M. P., \& Maslach, C. (1998). Burnout. In: H. Friedman (Ed.), Encyclopedia of Mental Health (pp. 347-357). San Diego, CA: Academic Press.

Lopez, J. M., Santiago, M. J., Godás, A., Castro, C., Villardefrancos, E., \& Ponte, D. (2008). An integrative approach to burnout in secondary school teachers: Examining the role of student disruptive behavior and disciplinary issues. International Journal of Psychology and Psychological Therapy, 8, 259-270.

Maddi, S. R., \& Kobasa S. C. (1984). The hardy executive: Health under stress. Homewood, IL: Dow Jones-Irwin.

Martin, J. J., Kelley, B., \& Eklund, R. C. (1999). A model of stress and burnout in male high school athletic directors. Journal of Sport \& Exercise Psychology, 21, 280294.

Maslach, C. \& Jackson, S. E. (1981). The measurement of experienced burnout. Journal of Occupational Behaviour, 2, 99-113.

Maslach, C. \& Jackson, S. E. (1986). Maslach Burnout Inventory (2nd Ed.) Palo Alto, CA: Consulting Psychologists Press.

Maslach, C., \& Leiter, M. P. (1997). The truth about burnout: How organizations cause personal stress and what to do about it. San Francisco, CA: Jossey-Bass. 
Maslach, C., Schaufeli, W. B., \& Leiter, M. P. (2001). Job burnout. Annual Review of Psychology, 52, 397-422. doi: 10.1146/annurev.psych.52.1.397

May, D. R., Gilson, R. L., \& Harter, L. M. (2004). The psychological conditions of meaningfulness, safety and availability and the engagement of the human spirit at work. Journal of Occupational and Organizational Psychology, 77, 11-37. doi: $10.1348 / 096317904322915892$

McCranie, E. W., Lambert, V. A., \& Lambert, C. E. (1987). Work stress, hardiness, and burnout among hospital staff nurses. Nursing Research, 36, 374-378,

McDougall, M. (2009, March 5). Importance of high employee engagement during recession leads organizations to participate in annual best employers in Canada study [Press release]. Retrieved from http://www.hewittassociates.com/intl/na/enca/AboutHewitt/Newsroom/PressReleaseDetail.aspx?cid=6399

Milliman, J., Czaplewski, A. J., \& Ferguson, J. (2003). Workplace spirituality and employee work attitudes: An exploratory empirical assessment. Journal of Organizational Change Management, 16, 426-447. doi:

$10.1108 / 09534810310484172$

Moorman, R. H. (1991). Relationship between organizational justice and organizational citizenship behaviors: Do fairness perceptions influence employee citizenship? Journal of Applied Psychology, 76, 845-855.

Neck, C. P., \& Milliman, J. F. (1994). Thought self-leadership: Finding spiritual fulfillment in organizational life. Journal of Managerial Psychology, 9, 9-16. 
Rhoades, L. \& Eisenberger, R. (2002). Perceived organizational support: A review of the literature. Journal of Applied Psychology, 87, 698-714. doi: 10.1037/00219010.87.4.698

Rhoades, L., Eisenberger, R. \& Armeli, S. (2001). Affective commitment to the organization: The contribution of perceived organizational support. Journal of Applied Psychology, 86, 825-36. doi: 10.1037/0021-9010.86.5.825

Rich, V. L., \& Rich, A. R., (1987). Personality hardiness and burnout in female staff nurses. Journal of Nursing Scholarship, 19, 63-66.

Riggs, M. L., Warka, J., Babasa, B., Betancourt, R., \& Hooker, S. (1994). Development and validation of self efficacy and outcome expectancy scales for job related applications. Educational and Psychological Measures, 54, 793-802. doi: $10.1177 / 0013164494054003026$

Rothbard, N. P. (2001). Enriching or depleting? The dynamics of engagement in work and family roles. Administrative Science Quarterly, 46, 655-684. doi: $10.2307 / 3094827$

Saks, A. M. (2006). Antecedents and consequences of employee engagement. Journal of Managerial Psychology, 21, 600-619. doi: 10.1108/02683940610690169

Schaufeli, W. B., Bakker, A. B., \& Salanova, M. (2006). The measurement of work engagement with a short questionnaire: A cross-national study. Educational and Psychological Measurement, 66, 701-716. doi: 10.1177/0013164405282471 
Schaufeli, W. B., Salanova, M., Gonzalez-Romá, V., \& Bakker, A. B. (2002). The measurement of engagement and burnout: A confirmative analytic approach. Journal of Happiness Studies, 3, 71-92. doi: 10.1023/A:1015630930326

Schaufeli, W. B. \& Bakker, A. B. (2001). Werk en welbevinden: Naar een positieve benadering in de Arbeids-en Gezondheidspsychologie [Work and well-being: Towards a positive Occupational Health Psychology] Gedrag \& Organisatie, 229253.

Schaufeli, W. B., \& Salanova, M. (2007). Efficacy or innefficacy, that's the question: Burnout and work engagement, and their relationships with efficacy beliefs. Anxiety, Stress and Coping, 20, 177-196. doi: 10.1010/10615800701217878

Schaufeli,W. B., Leiter, M. P., Maslach, C.,\& Jackson, S. E. (1996). Maslach Burnout Inventory-General Survey. In C. Maslach, S. E. Jackson, \& M. P. Leiter (Eds.), Maslach Burnout Inventory—Test manual (3rd ed., pp. 22-26). Palo Alto, CA: Consulting Psychologists Press.

Schwartzer, R. (Ed.). (1992). Self-efficacy. Thought control of action. Washington, DC: Hemisphere.

Seppala, P., Mauno, S., Feldt, T., Hakanen, J., Kinnunen, U., Tolvanen, A., \& Schaufeli, W. B., (2009). The Construct Validity of the Utrecht Work Engagement Scale: Multisample and Longitudinal Evidence. Journal of Happiness Studies, 10, 459481. doi: 10.1007/s10902-008-9100-y 
Spreitzer, G. M., Kizilos, M. A., \& Nason, S. W. (1997). A dimensional analysis of the relationship between psychological empowerment and effectiveness, satisfaction, and strain. Journal of Management, 23, 679-704. doi: 10.1016/S01492063(97)90021-0

Topf, M. (1989). Personality hardiness, occupational stress, and burnout in critical care nurses. Research in Nursing and Health, 12, 179-186. doi: 10.1002/nur.4770120308

Turnipseed, L. (1999). An exploratory study of the hardy personality at work in the healthcare industry. Psychological Reports, 85, 1199-1217. doi: 10.2466/PR0.85.7.1199-1217

US unemployment reaches 9.7 in August. (2009, September). San Francisco Center for Economic Development. Retrieved from http://www.sfced.org/aboutsfced/press/2009/us-unemployment-reaches-9.7-in-august 


\section{Appendix}

Survey Items

Perceived organizational support: Survey of perceived organizational support (SPOS). 8item short form. (Rhoades, Eisenberger, \& Armeli, 2001)

1. My organization really cares about my well-being.

2. My organization strongly considers my goals and values.

3. My organization shows little concern for me. (R)

4. My organization cares about my opinions.

5. My organization is willing to help me if I need a special favor.

6. Help is available from my organization when I have a problem.

7. My organization would forgive a honest mistake on my part.

8. If given the opportunity, my organization would take advantage of me. (R)

. Job characteristics (autonomy, task identity, skill variety, task significance, feedback from others, feedback from the job). 7 items from the Job Diagnostic Survey (Hackman \& Oldham, 1980)

Hackman, J.R. and Oldham, G.R. (1980), Work Redesign, Addison-Wesley, Reading, MA.

1. There is a lot of autonomy in my job. I decide on my own on how to do my work.

2. My job involves doing a "whole" and identifiable piece of work. (In other words, the job is complete piece of work that has an obvious beginning and end.).

3. There is a lot of variety in my job. (In other words, the job requires me to do many different things at work, using a variety of my skills and talents.).

4. My job is significant. (In other words, the results of my work are likely to significantly affect the well-being of other people).

5. My managers let me know how well I am doing in my job.

6. My coworkers let me know how well I am doing in my job.

7. My work itself tells me how well I am doing in my job. (In other words, the actual work itself provides clues about how well I am doing aside from any "feedback" coworkers or supervisors may provide. 
Procedural justice (Moorman, 1991)

My company follows formal decision making procedures to:

1. collect accurate information necessary for making decisions.

2. provide opportunities to appeal or challenge the decision.

3. .have all sides affected by the decision represented.

4. .generate standards so that decisions could be made with consistency.

5. hear the concerns of all those affected by the decision.

6. provide useful feedback regarding the decision and its implementation.

7. allow for requests for clarification or additional information about the decision.

Psychological hardiness. short form of the Dispositional Resilence Scale (DRS15-R) (Bartone, 2007

1. Most of my life gets spent doing things that are meaningful.

2. Planning ahead can help avoid most future problems.

3. I don't like to make changes in my regular activities. (R)

4. I feel that my life is somewhat empty of meaning. (R)

5. Changes in routine are interesting to me.

6. By working hard you can nearly always achieve your goals.

7, I really look forward to my work activities.

8. If I'm working on a difficult task, I know when to ask for help.

9. I don't think there's much I can do to influence my own future. (R)

10.Trying your best at work is really worth it in the end.

11. It bothers me when my daily routine gets interrupted. (R)

12. Most days, life is really interesting and exciting for me.

13. I enjoy the challenge when I have to do more than one thing at a time.

14. I like having a daily schedule that doesn't change very much. (R)

15. When I make plans I'm certain I can make them work.

Self efficacy: Personal Efficacy Beliefs Scale (Riggs, Warka, Babasa, Betancourt, \& Hooker, 1994)

1. I have confidence in my ability to do my job.

2. There are some tasks required by my job that I cannot do well. (R)

3. When my performance is poor, it is due to my lack of ability. (R)

4. I doubt my ability to do my job. (R)

5. I have all the skills needed to perform my job very well.

6. Most people in my line of work can do this job better than I can. (R)

7. I am an expert at my job.

8. My future in this job is limited because of my lack of skills. (R) 
9. I am very proud of my job skills and abilities

10. I feel threatened when others watch me work. (R)

Work engagement. Utrecht Work Engagement Scale 9 item short form (Schaufeli et al., 2006)

1. At my work, I feel that I am bursting with energy.

2. At my job, I feel strong and vigorous.

3. I am enthusiastic about my job.

4. My job inspires me.

5. When I get up in the morning, I feel like going to work.

6. I feel happy when I am working intensely.

7. I am proud of the work that I do.

8. I am immersed in my work.

9. I get carried away when I'm working.

Organizational engagement (Saks, 2006)

1. Being a member of this organization is very captivating.

2. One of the most exciting things for me is getting involved with things happening in this organization.

3. I am really not into the "goings-on" in this organization. (R)

4. Being a member of this organization make me come "alive."

5. Being a member of this organization is exhilarating for me.

6. I am highly engaged in this organization.

\section{Demographic questions}

What is your current age?

What is your gender?

On average, how many hours do you work in a week?

Please give a general description of your occupational family

(ex: Human Resources, Information Technology, Sales, Finance, etc)

Please give a general description of your occupation

(ex: I am: an HR Generalist; a Network Engineer; a sales representative; an accountant)

Please give a general description of the industry in which you work

(ex: Manufacturing, Healthcare, Education, Technology Development)

Please check the single response that best describes your educational background I completed high school. 
I completed high school and some college courses.

I completed high school and have a professional certification/license.

I hold a Bachelor's degree.

I hold a Bachelor's degree and completed some graduate courses.

I hold a Bachelor's degree and have a professional certification/license.

I hold a Master's degree or higher.

I hold a Master's degree or higher and also have a professional certification/license. 


\section{Appendix B}

\section{IRB Approval to Conduct Research}

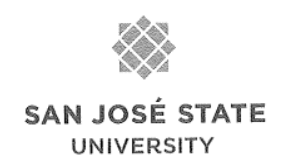

Office of the Provost

Associate Vice President Graduate Studies \& Research

One Washington Square San José, California 95192-0025

Voice: $408-924-2427$

Fax: 408-924-2612

gradestudies@sjsu.edu

www.sjsu.edu
To: Andrea Kittredge

From: Pamela Stacks, Ph.D.

Associate Vice President

Graduate Studies and Research

Date: September 25, 2009

The Human Subjects-Institutional Review Board has registered your study entitled:

"Predicting Work and Organizational Engagement with Workplace and Personality Variables"

This registration, which provides exempt status under Exemption Category 2, of SJSU Policy SO8-7, is contingent upon the subjects included in your research project being appropriately protected from risk. This includes the protection of the confidentiality of the subjects when they participate in your research project, and with regard to all data that may be collected from the subjects. The approval includes continued monitoring of your research by the Board to assure that the subjects are being adequately and properly protected from such risks. If at any time a subject becomes injured or complains of injury, you must notify Dr. Pamela Stacks, Ph.D. immediately. Injury includes but is not limited to bodily harm, psychological trauma, and release of potentially damaging personal information. This approval for the human subject's portion of your project is in effect for one year, and data collection beyond September 25, 2010 requires an extension request.

Please also be advised that all subjects need to be fully informed and aware that their participation in your research project is voluntary, and that he or she may withdraw from the project at any time. Further, a subject's participation, refusal to participate, or withdrawal will not affect any services that the subject is receiving or will receive at the institution in which the research is being conducted. If you have any questions, please contact me at (408) 924-2427.

Protocol \# S0904027

cc. Howard Tokunaga 0120 